\title{
Importancia de la epistemología en la consolidación de la psicología como ciencia
}

\author{
Importance of epistemology in the consolidation of psychology as a science
}

Rodrigo Rodríguez-Terán ${ }^{a}$, Ernesto Cotonieto-Martínez ${ }^{b}$

\begin{abstract}
:
The epistemology is a science, derived from philosophy, which is responsible for studying the theory and fundamentals of scientific method. In other words, the knowledge acquired through a set of steps structured carefully that goes beyond the knowledge acquired through experience. This document takes up the object of study of psychology, addresses the relationship of psychology with empiricist and rationalist epistemology and discusses the way that this discipline have to follow to achieve its consolidation as a science. Finally, we conclude that epistemology is the main tool that psychology has to separate the evidence-based practice and the pseudo-scientific methods without social value.
\end{abstract}

\section{Keywords:}

Philosophy, Knowledge, Scientific method, Evidence-Based Practice.

\begin{abstract}
Resumen:
La epistemología es una ciencia, derivada de la filosofía, que se encarga de estudiar la teoría y los fundamentos del método científico; es decir, del conocimiento adquirido mediante el uso de una serie de pasos cuidadosamente estructurados y que va más allá del conocimiento adquirido con la experiencia. El presente documento retoma el objeto de estudio de la psicología, aborda la relación de la psicología con las epistemologías empiristas y racionalistas, y discute el camino que la disciplina debe seguir para alcanzar su consolidación como ciencia. Finalmente, se concluye que la epistemología es la principal herramienta que la psicología tiene a su disposición para separar la práctica basada en evidencia y los métodos pseudocientíficos carentes de valor social.
\end{abstract}

\section{Palabras Clave:}

Filosofía, Conocimiento, Método científico, Práctica basada en evidencia.

\section{INTRODUCCIÓN}

La filosofía estudia todas las cosas a la luz natural de la razón; en donde el intelecto es su más grande herramienta, así como su propia limitación. A partir de esta definición, es posible identificar a dos ciencias capaces de estudiar el conocimiento, así como la forma en la que explican la obtención de un intelecto in crescendo.

Por un lado, podemos encontrar a la gnoseología, palabra que proviene del griego gnosis, eōs y logía, que hace referencia al estudio del conocimiento. Pero, ¿De qué tipo de conocimiento estamos hablando?, tal y como se marca de manera general, el conocimiento que estudia la gnoseología es el conocimiento vulgar, empírico, aprehendido de cierta manera como "ensayo y error".

Por otra parte, la epistemología (que también proviene del griego epistếmē 'conocimiento' y logía 'estudio') hace referencia al estudio del conocimiento científico en su totalidad. De hecho, la Real Academia Española [1], la define como la teoría de los fundamentos y métodos del método científico.

\footnotetext{
${ }^{a}$ Universidad Privada del Estado de México, https://orcid.org/0000-0002-1821-2066, Email: roll.royce9910@gmail.com

${ }^{\mathrm{b}}$ Autor de Correspondencia, Universidad Autónoma del Estado de Hidalgo, Instituto de Ciencias de la Salud,

https://orcid.org/0000-0001-5639-5898, Email: cotonietoe@gmail.com
} 
La principal diferencia es que la primera se trata de la teoría del conocimiento empírico y la segunda estudia el conocimiento adquirido mediante pasos cuidadosamente estructurados, que van más allá de la experiencia cotidiana casual.

Al principio, la epistemología no era más que una rama de la filosofía sin mucha utilidad, era más conocida como un capítulo de la teoría del conocimiento o gnoseología. Aún no se había advertido los problemas semánticos, ontológicos, axiológicos, éticos y de otro tipo que se presenten tanto en el curso de la investigación científica como en el de la reflexión meta-científica [2].

De hecho, la epistemología no tuvo un cambio radical, en términos de su utilidad, sino hasta después de la fundación del Positivismo Lógico o también llamado Circulo de Viena en 1924. Se trató de una reformulación del positivismo Comtiano, que consideraba que todo aquello no susceptible de expresarse en términos matemáticos a través de los cuales fuese posible hacer observaciones objetivas el mundo, no debía ser considerado como ciencia [3].

Por lo que la epistemología fue vista como una ciencia que debía practicar y desarrollar una filosofía more geométrico (propuesta hecha por Bertrand Russell), y en particular con la ayuda de la lógica matemática. Paradójicamente, los miembros del Círculo de Viena tenían un defecto fatal en su epistemología: esta estaba atada a la tradición empirista e inductista, la cual era incompatible con la epistemología realista inherente al enfoque científico [2].

Sin embargo, los cuestionamientos y alineaciones con las formulaciones de este grupo "neopositivista" permitieron el desarrollo y técnicas de matemáticas y estadísticas aplicadas al campo de investigación de las ciencias sociales [3].

\section{El método científico como objeto de estudio}

Con base en lo expuesto previamente, debemos enfatizar que la epistemología es la rama de la filosofía que estudia la investigación científica y su producto, el conocimiento científico. De tal forma, se puede redirigir la atención hacia la principal herramienta del objeto de estudio: el método científico.

El método que pregonó Bacon, a principios del siglo XVII, fue inductivo; pues para él, el método científico consistía en un conjunto de reglas que moldeaban cómo se debían observar fenómenos e inferir conclusiones a partir de dichas observaciones. De modo que las reglas de Bacon eran sencillas y no requerían talento ni preparación previa para aplicarlas y que avanzara la ciencia.

Por el contrario, para Descartes a mediados del siglo XVII, considera que se debía poder partir de principios supremos, de naturaleza metafísica y aún teológica, para obtener de ellos verdades matemáticas y verdades acerca de la naturaleza y el hombre [2], su método por ende era el de análisis y deducción debido a que menospreciaba la experiencia a la par que Bacon exageraba la importancia de la misma e ignoraba la experimentación y la existencia de teorías, en particular las teorías matemáticas.

Sin embargo, para que el método científico fuera como su nombre lo dice "científico", es menester, que la investigación se apropie de ciertos conocimientos, advierta qué se ignora, escoja qué se quiere averiguar, planea la manera de hacerlo, etc. [2]. Además, debe incluir un conjunto de procedimientos premeditados, predefinidos, ordenados y sensibles de someterse a replicación, a través de los cuales sea posible generar conocimiento, y que a su vez éste último sea producto de un análisis crítico y racional de los resultados [4].

Todo esto con el fin de proveer a la epistemología los estudios necesarios para que la misma filosofía ratifique el sentido estricto de lo que es el método científico. De tal modo que la epistemología (incluyendo su objeto de estudio) es de vital importancia en las ciencias sociales, especialmente por la constante necesidad de dar un sustento científico lo suficientemente fuerte como para acercarse a una "verdad absoluta" respecto a los fenómenos sociales.

De ahí que a lo largo de la historia hayan surgido diferentes epistemologías, así como una transformación sui generis de manera general en la epistemología. Y esta fundamental transformación del conocimiento-estado en conocimiento-proceso obliga a replantear el problema de las relaciones entre la epistemología y el desarrollo e incluso la formación psicológica de las nociones y de las operaciones [5].

\section{DESARROLLO El objeto de estudio de la psicología}

Etimológicamente hablando, la psicología se compone de dos raíces: psique que significa alma y logía que significa estudio o tratado, de tal forma que la palabra misma hace referencia al estudio del alma.

Sin embargo, al igual que la filosofía, el término psicología ha sido definido de diversas maneras a lo largo de los 
años desde su origen en la antigua Grecia con Platón y Aristóteles y hasta después el auge del cientificismo de dicha disciplina gracias al contexto y la osadía del método experimental de Wilhelm Wundt en 1879 (con la creación del laboratorio en Leipzig).

Tal y como lo señaló Kuhn en 1971, los paradigmas dentro de la psicología han ido sufriendo muchas revoluciones que se han visto reflejadas en la fundación y reconfiguración de las escuelas de psicología como el estructuralismo de Wundt, el funcionalismo de James, la Gestalt alemana, el psicoanálisis, el conductismo y el cognitivismo entre otras corrientes contemporáneas emergentes [6].

Lo que, en consecuencia, ha dificultado llegar a un consenso claro respecto a la definición de lo que es la psicología y cuál es su dominio o campo de estudio; y sin embargo, todos enfoques comparten una necesidad en común: la de otorgarle un estatus científico a la psicología, aceptada en mayor o menor medida por cada uno de ellos y a partir de su propia metodología (cualitativa o cuantitativa).

Y ese es el motivo principal por el cual se debe acudir a la epistemología, ya que ésta permite estructurar a la psicología como una ciencia. Por ejemplo, cuando se cuestiona el estatus científico de la psicología, uno de los aspectos que se discute es el carácter empirista de esta disciplina.

\section{Génesis: la experiencia}

Autores como Canguilhem (1970) [7] y Deleule (1972) [8] consideran que el empirismo es uno de los mayores problemas que presenta la psicología; otros, como Boring (1980), consideran que la tradición empirista es la progenitora de la psicología experimental y que el empirismo enriqueció y complementó los problemas estudiados por la psicología. Tan así, que Locke (1956) con su epistemología empirista se planteó el problema de determinar qué es el conocimiento verdadero a través de su fundamentación: la experiencia [6].

Por ejemplo, las exigencias de la epistemología empirista encaminaron a Locke en la búsqueda de explicaciones a fenómenos psicológicos como: la constitución del entendimiento, el origen de las ideas, así como las facultades que operan en el propio entendimiento.

En este sentido, podemos destacar que, si la experiencia es la fuente del conocimiento del mundo físico, si es aquello a partir de lo cual se establece el entendimiento, esa experiencia y su origen deben conocerse. En consecuencia, lo psicológico es reconocido como una región específica del conocimiento [6].

\section{Epistemología empírica}

En la historia de las epistemologías clásicas sólo las corrientes empiristas recurrieron a la psicología, por razones fáciles de comprender, aunque éstas no expliquen ni la escasa preocupación por la verificación psicológica de las otras escuelas ni la excesivamente sumaria psicología con que se contentó el propio empirismo [5].

Las razones aludidas están, naturalmente, relacionadas con el hecho de que, si se quiere dar cuenta de la totalidad de los conocimientos sólo a partir de la experiencia, para justificar tal tesis no queda más remedio que tratar de analizar lo que es la experiencia, lo cual implica recurrir a percepciones, asociaciones y hábitos, que son procesos psicológicos.

Pero como las filosofías empiristas y sensualistas nacieron mucho antes que la psicología experimental, tuvieron que contentarse con unas nociones procedentes del sentido común y con una descripción más bien especulativa. Limitación que impidió ver que la experiencia es siempre asimilación a estructuras y que no permitió dedicarse a un estudio sistemático del ipse intellectus [5].

\section{Epistemología platónica}

En cuanto a las epistemologías platónicas, racionalistas o aprioristas, cada una de ellas creyó encontrar algún fundamental instrumento de conocimiento que fuera ajeno, superior o anterior a la experiencia [5]. Pero, como consecuencia de un olvido que sin duda se explica también por las tendencias especulativas y por el desprecio a la verificación efectiva, estas doctrinas no pasaron de su preocupación por caracterizar las propiedades que atribuían al citado instrumento (la reminiscencia de las ideas, el poder universal de la Razón o el carácter previo y necesario a la vez de las formas a priori) al negarse a verificar si éste se hallaba realmente a disposición del sujeto. $Y$, sin embargo, quiérase o no, se trata de una cuestión de hechos.

Por un lado, la cuestión de la reminiscencia platónica o de la Razón universal es relativamente simple: resulta evidente que antes de conferir tales «facultades» a «todos» los seres humanos normales, convendría 
examinarlos; y este examen muestra rápidamente las dificultades de la hipótesis.

Por otra parte, las formas a priori en donde el análisis de los hechos es más delicado, puesto que no basta con examinar la conciencia de los sujetos, sino que hay que ver sus condiciones previas y, por hipótesis, el psicólogo que quisiera estudiarlas las utilizaría como condiciones previas de su investigación [5].

A pesar de esto, también con la historia en sus múltiples dimensiones (la historia de las ciencias, sociogénesis y psicogénesis) y si la hipótesis es verdadera debe verificarse no en la introspección de los sujetos, sino en el examen de los resultados de su trabajo intelectual.

\section{El raciocinio, la diferencia}

Si bien es cierto que toda experiencia supone condiciones previas para el conocimiento científico, no por ello éstas presentan, sin más, necesidad lógica o intrínseca, y aunque varias formas de conocimiento conducen a la necesidad de experiencia, el uso se sitúa al final y no en el punto de partida. De ahí la importancia del raciocinio como la clave para la generación del conocimiento científico.

El ser humano pertenece a varios géneros como son: viviente, ser sustancia, animal, ser, ser corpóreo, y en específico a su género más próximo: el "ser animal". Como tal, obedece la lógica del mecanicismo. Por ello, la "psicofisiología cartesiana" no es algo específico y particularmente humano, sino que se refiere a la "animalidad en general" [6].

Sin embargo, a pesar de estar sujeto a las leyes del mecanicismo, el ser humano es un animal racional, por lo tanto, esta definición expresa la esencia, la naturaleza o, lo que es lo mismo, la forma sustancial del hombre [9]. En este sentido, Descartes afirmaba que el hombre era el resultado de la unión esencial entre cuerpo y alma (también llamada "razón"). Y para él, este atributo de dualidad era precisamente lo que distinguía sustancialmente al ser humano de los animales.

Por lo tanto, la mejor definición que se puede acercar a lo que es el hombre es la que incluya características innatas del ser humano como son la toma de decisiones o la posibilidad de hacerse responsable de sus propias acciones; es decir, su capacidad de raciocinio.

\section{Hacia la consolidación como ciencia}

La psicología es, en cierto modo, una disciplina "epistemológicamente atormentada", monstruosa y bicéfala (que posee dos maneras de pensar y concebir la propia realidad del ser humano). La razón de este tormento epistemológico tiene que ver con el hecho de que el sentido histórico de la psicología pasa por la construcción de antropologías naturalistas que permitan tramitar el problema de la subjetividad desde la neutralidad fáctica propia de las ciencias naturales [10].

Lo hace desde el principio (y como ejemplo está la obra del mismo Wundt) moviéndose agónicamente entre los polos de la naturaleza y la cultura, entre la voluntad de explicar la subjetividad y el impulso irrenunciable de comprenderla. Esta vocación histórica de la psicología la convierte en un territorio inestable y frágil, de geometría variable [10].

La crisis en la que la psicología se desenvuelve desde sus orígenes no puede ser entendida como un estado de transición, sino más bien como un período de consolidación epistemológica que llegará a ser superado si la disciplina consigue identificar y vincularse de manera positiva con los supuestos de la lógica que han servido a las ciencias naturales.

Cuando la psicología defiende científicamente la idea de que la ciencia es el proyecto límite de la naturaleza, a través del despliegue de la razón (haciendo referencia a la epistemología racionalista), cierra un bucle histórico; acaba, por así decirlo, con el misterio y certifica el destino del hombre y convierte, por la misma razón, el sistema de valores que guía el desarrollo de la cultura occidental en el único pensable [10].

Por esa vía, la psicología se coloca en el corazón de la máquina cultural (haciendo referencia a la sociedad misma como creadora e influencia del ser humano en términos culturales), creando un espacio que proyecta, refleja y refracta imágenes del hombre fundamentales para definir en cada momento la dirección, el ethos necesario para que las cosas vayan por donde deben ir.

Finalmente, considerando que las limitaciones para definir a la psicología son consecuencia de la gran variedad de corrientes teóricas existentes en la disciplina [11], es importante destacar que aún existe la esperanza de establecer un hilo conductor común y capaz de unificarlas: el método científico. $Y$ esto es debido a que ha demostrado ser el único camino capaz de integrar y redefinir el papel de conceptos como mente, psique y 
conciencia, incorporándolos en el ámbito de la investigación con un nuevo enfoque y significado.

Lo que es lo mismo, cuando la psicología "naturaliza" el método científico (es decir, hace necesaria e inevitable la actividad científica), necesariamente adopta la estructura al que toda ciencia, verdadera ciencia, corresponde y que ella misma reproduce [10].

\section{CONCLUSIONES}

La enorme necesidad del progreso "en beneficio" del ser humano, ha causado que la ciencia se convierta en el eje de la cultura contemporánea (el cual marca cuál debe ser el modo de vida de la sociedad y que se ve afectado por causa del progreso científico), ésta ha sido tomada como objeto de estudios de varias disciplinas, cuya unión constituye la ciencia de las ciencias [2].

En específico, la relación entre epistemología y psicología puede ser algo difícil de entender debido a que podría implicar el uso excesivo de conceptos (aunque no necesariamente sea indebido) entre cada una de estas disciplinas. Aunque podemos comenzar señalando un objetivo en común; ambas buscan llegar al conocimiento científico en su totalidad; ya que, sin éste, la psicología no podría colocarse en calidad de ciencia, delegándose por consecuencia a una limitada y vacía pseudociencia (Figura 1).

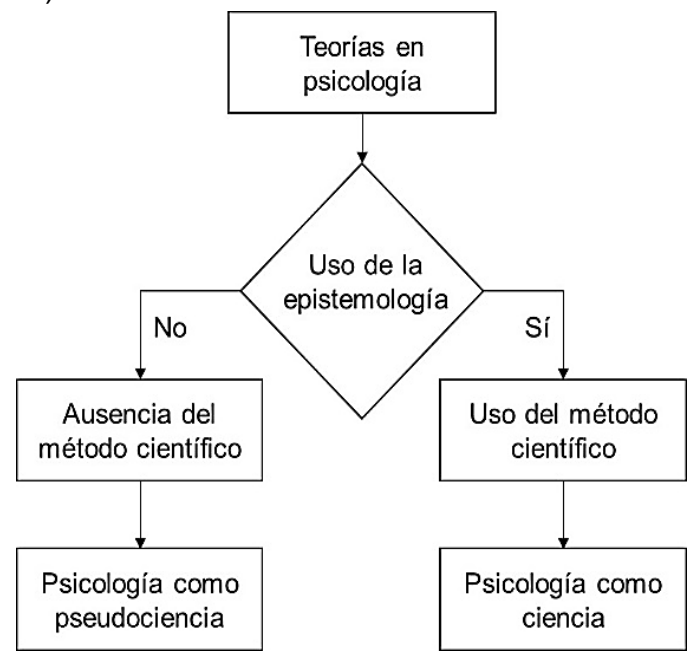

Figura 1. Epistemología: diferencia entre ciencia y pseudociencia en psicología

Pensemos en que la epistemología psicológica puede entenderse en dos sentidos: a) como una reflexión sobre el conocimiento que adquiere el psicólogo sobre un objeto, y b) como una reflexión sobre el conocimiento que adquiere el psicólogo sobre un sujeto capaz de representarse en los objetos. En primera instancia no se observarían diferencias en estos dos sentidos, pero no es así, tal como lo es en el método científico (que todo dependerá del orden del proceso o incluso de un solo paso a seguir), de la misma forma estos dos sentidos para concebir la epistemología psicológica son separados por una sencilla razón.

En el primero, la epistemología se limita a describir hechos, mientras que en el segundo se da un paso más: busca interpretarlos; por lo que la epistemología debe centrarse en el estudio de los métodos que usa la psicología, y en la forma en la cual intenta explicar las conductas y otros procesos de interés para la disciplina [12].

Concretamente, una manifestación de la convergencia teórica-práctica de ambos sentidos la podemos identificar en una definición; recordemos que la American Psychological Association [13] como institución que aglutina una gran cantidad de miembros, ha definido a la psicología como la ciencia encargada del estudio de la mente y el comportamiento, así como de aspectos específicos como las actitudes y los rasgos de personalidad (2018).

Dicha definición tiene implicaciones que no deben tomarse a la ligera, ya que involucra la descripción y establecimiento de causas a partir del uso del método científico; dicho de otro modo, aquellas prácticas que no se encuentren basadas en evidencia científica tampoco corresponden al terreno de la epistemología racionalista.

Sin embargo, no es un secreto que la psicología como disciplina aún se enfrenta a muchos retos, hasta el momento ha sido insuficiente la difusión de sus aportaciones en el ámbito educativo, organizacional o de la salud, y precisamente esto podría ser explicado por las malas prácticas de herencia pseudocientífica que no han permitido generar valor social. Por ello es que la epistemología es y será el brazo fuerte de la psicología en su consolidación como ciencia, lo que incrementa su importancia en la formación de nuevos profesionales y en la actualización de aquellos que cuentan con experiencia, pero carecen de fundamentos epistemológicos que permitan su inserción a la práctica basada en evidencia. 


\section{REFERENCIAS}

[1] Real Academia Española. Diccionario [Internet]. . 2019 [Consultado 18 Dic 2019]. Disponible en: https://dle.rae.es/diccionario

[2] Bunge M. Epistemología. Buenos Aires: Siglo XXI Editores; 2002.

[3] Londoño DH Reconfiguración de las perspectivas epistemológicas del desarrollo. Sophia, 2007. 3: 43-55. Disponible en: https://www.redalyc.org/pdf/4137/413740746004.pdf

[4] Torre-Bouscoulet L. El método científico: la mejor herramienta clínica. Neumol. cir. torax. 2016. 75(3): 205-6. Disponible: http://www.scielo.org.mx/scielo.php?script=sci_arttext\&pid=S002837462016000300205

[5] Piaget J. Psicología y Epistemología. España: Planeta-De Agostini; 1985.

[6] Medina JA. Psicología y epistemología: hacia una psicología abierta. México: Trillas; 2019.

[7] Canguilhem G. ¿Qué es la Psicología? Rev. colomb. Psicol. 1998 1(7): 7-14. Disponible en: https://dialnet.unirioja.es/ejemplar/352485

[8] Deleule D. La Psicología, mito científico. Barcelona: Anagrama; 1972.

[9] García-Alonso L. El Hombre: Su conocimiento y libertad. México: Anáhuac del Sur; 2000.

[10] Blanco F. Epistemología y Psicología: Un Viaje de Ida y Vuelta. Madrid: Universidad Autónoma de Madrid; 2002.

[11] Esteban YK. Una evaluación epistemológica de la psicología como ciencia. Horizonte de la Ciencia. 2015. 5(8): 47-54. Disponible en: https://dialnet.unirioja.es/servlet/autor?codigo=3895773

[12] Greco P. Epistemología de la psicología. En: Piaget J. Lógica y conocimiento científico, VI: Epistemología de las ciencias humanas. Buenos Aires: Proteo; 1972.

[13] American Psychological Association. Dictionary of Psychology [Internet]. 2018. [Consultado 15 Dic 2019] Disponible en: https://dictionary.apa.org/psychology 